\title{
JOUBERT SYNDROME IN THREE ADULTS IN A FAMILY: A CASE SERIES
}

\author{
Dipu Bhuyan ${ }^{1}$, Pankaj Kr. Patel ${ }^{2}$, Rohit Kr. Chandak ${ }^{3}$, Sushant Agarwal ${ }^{4}$, Sudip Paul ${ }^{5}$
}

\section{HOW TO CITE THIS ARTICLE:}

Dipu Bhuyan, Pankaj Kr. Patel, Rohit Kr. Chandak, Sushant Agarwal, Sudip Paul. "Joubert Syndrome in Three Adults in a Family: A Case Series". Journal of Evolution of Medical and Dental Sciences 2015; Vol. 4, Issue 76, September 21; Page: 13255-13261, DOI: 10.14260/jemds/2015/1906

\begin{abstract}
Joubert syndrome (JS) is a rare autosomal recessive central nervous system malformation characterized by hypoplasia of the cerebellar vermis, hypotonia and abnormal psychomotor development, along with altered respiratory pattern and various ophthalmologic features. Here, we describe three adult with Joubert syndrome in a family that had almost similar presentations, including ataxia, developmental delay, mental retardation and ocular disorders. Prevalence of Joubert syndrome is about 1 in 100,000 live birth. It may be accompanied by other organs' disorders. The molar tooth sign is pathognomonic for joubert syndrome that is ascertained by brain MRI.
\end{abstract}

KEYWORDS: Joubert syndrome; Molar tooth sign; Vermian dysgenesis.

INTRODUCTION: Joubert syndrome (JS) is a rare autosomal recessive central nervous system malformation characterized by hypoplasia of the cerebellar vermis, hypotonia and abnormal psychomotor development, together with altered respiratory pattern and various ophthalmologic features.(1) Other common characteristics of this syndrome are ataxia, oculomotor apraxia, developmental delay and mental retardation.(2)

Estimates of the incidence of JS ranges between 1/80,000 and 1/100,000 live births and its recurrence risk is $25 \%$ in most families.(3) Renal insufficiency is rarely reported in JS.(4) Location of the affected gene of this disorder has not been definitely identified.(5) so, clinical and radiological signs are necessary for diagnosis of JS. Magnetic resonance imaging (MRI) has revolutionized the diagnosis of Joubert syndrome. It revealed the midbrain malformations included fourth ventricle dilatation and superior cerebellar peduncle elongation, which forms the classically described "Molar tooth sign".(6) After the first months of life, global prognosis considerably varies among JS subgroups depending on the extent and severity of organs involvement.(3)

Here we describe three cases of JS in a family with mental and ocular presentations.

CASE REPORT: We want to report three adult with JS in a family with the same presentations.

Case 1: The first adult of the family is a 26 years old male, with history of mental retardation, developmental delay, poor vision referred to guwahati Medical College for evaluation. His mother recalls that the patient could hold his head steady while sitting at age of one year and could sit independently at age of two years. He walked alone in age of four years. Tooth eruption occurred at age of one year. Bowel and bladder control emerged at age of four years. He also suffers from mental retardation, failure to thrive (FTT), strabismus, decreased visual acuity in both eye and aggressive behavior. He can put the words together but is not able to make a complete sentence and is on speech therapy.

Proximal and distal forces are normal. Deep tendon reflexes are normal too, but toe to heal test is abnormal. His ultrasonography is normal, and has no history of any considerable respiratory disorder. 


\section{CASE REPORT}
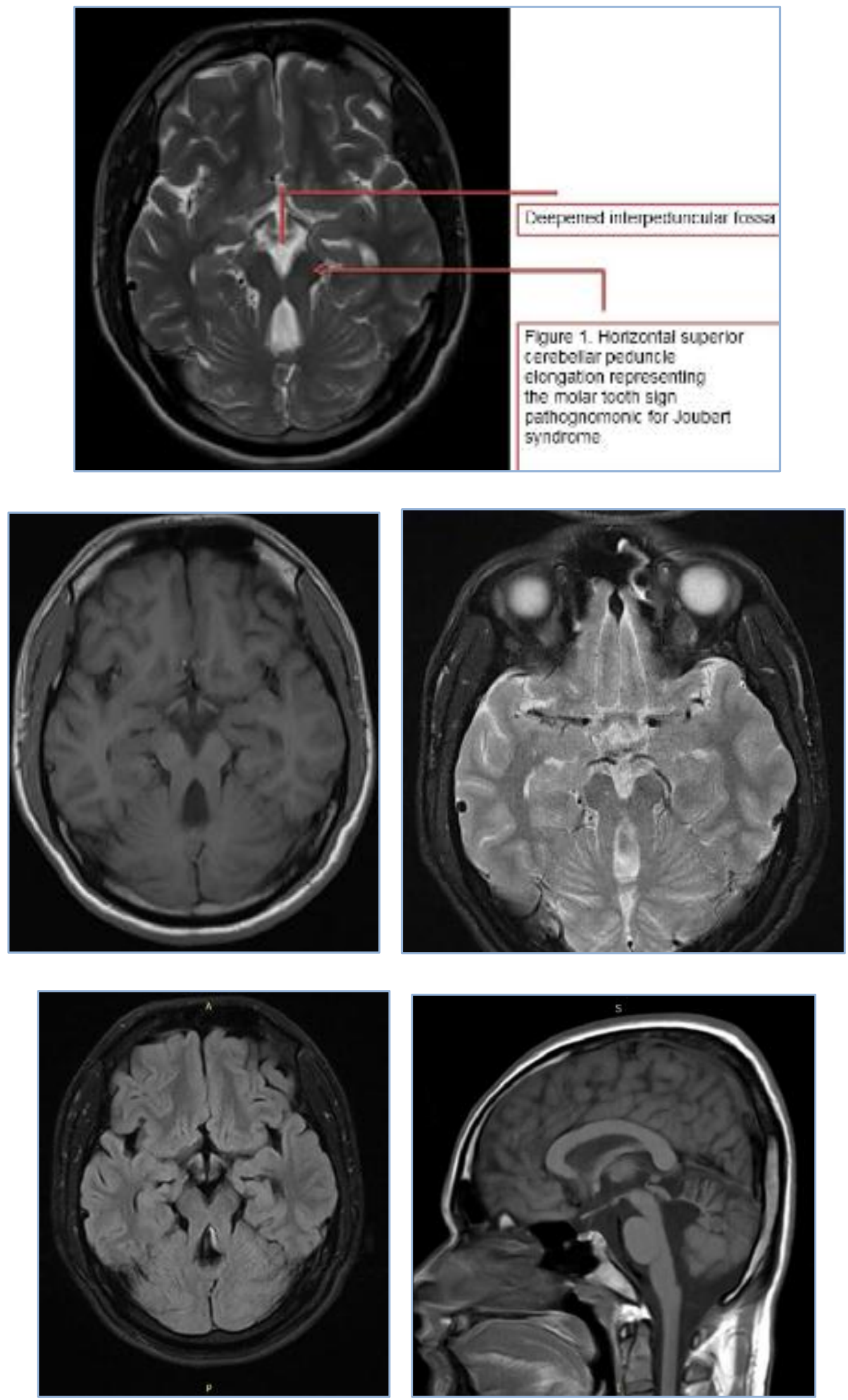


\section{CASE REPORT}

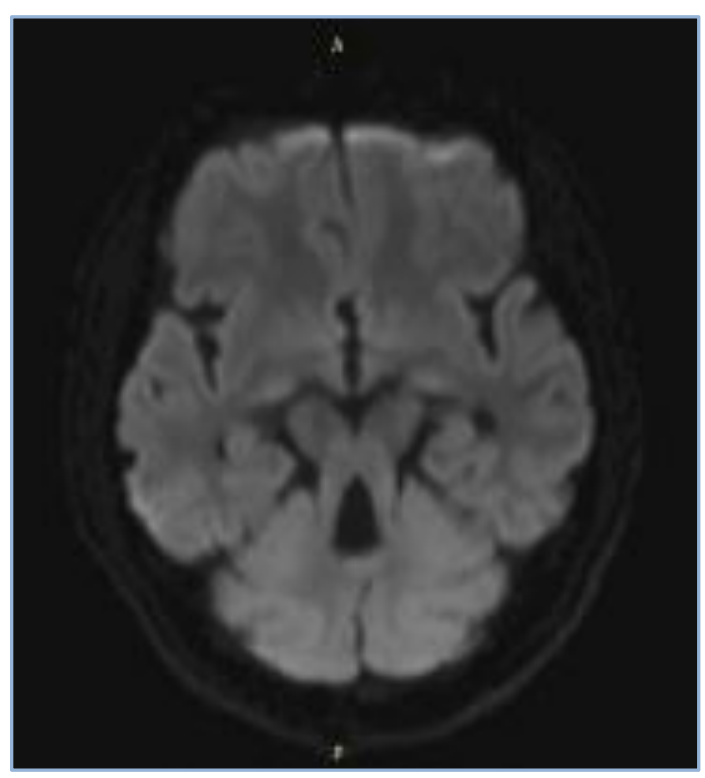

Case 2: He is a 28 years old male with the same symptoms and signs as his brother, except some differences. He has developmental delay, FTT, mental retardation and decreased visual acuity in both eyes. He doesn't have aggressive behavior. His development was as same as his brother. Neurologic examinations and laboratory and imaging results were also similar.

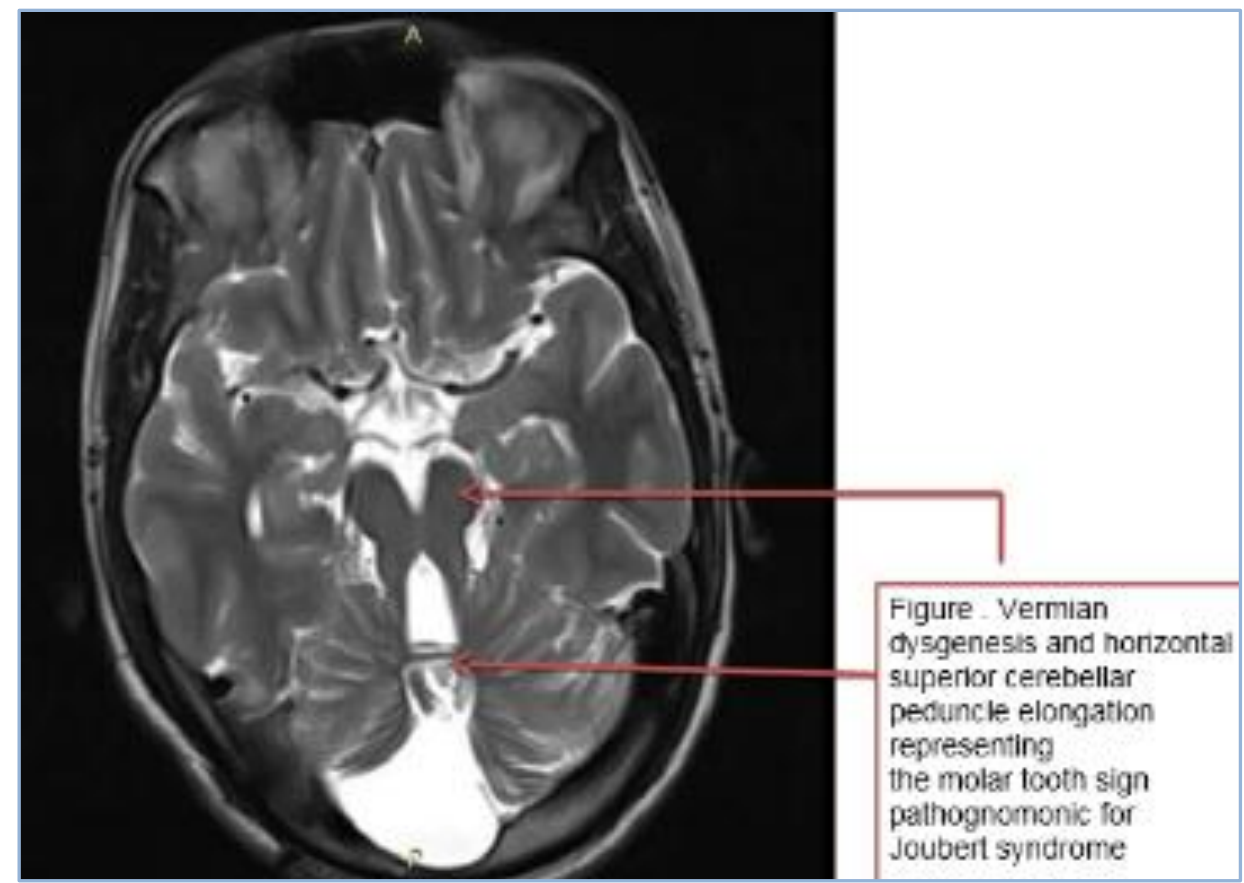




\section{CASE REPORT}
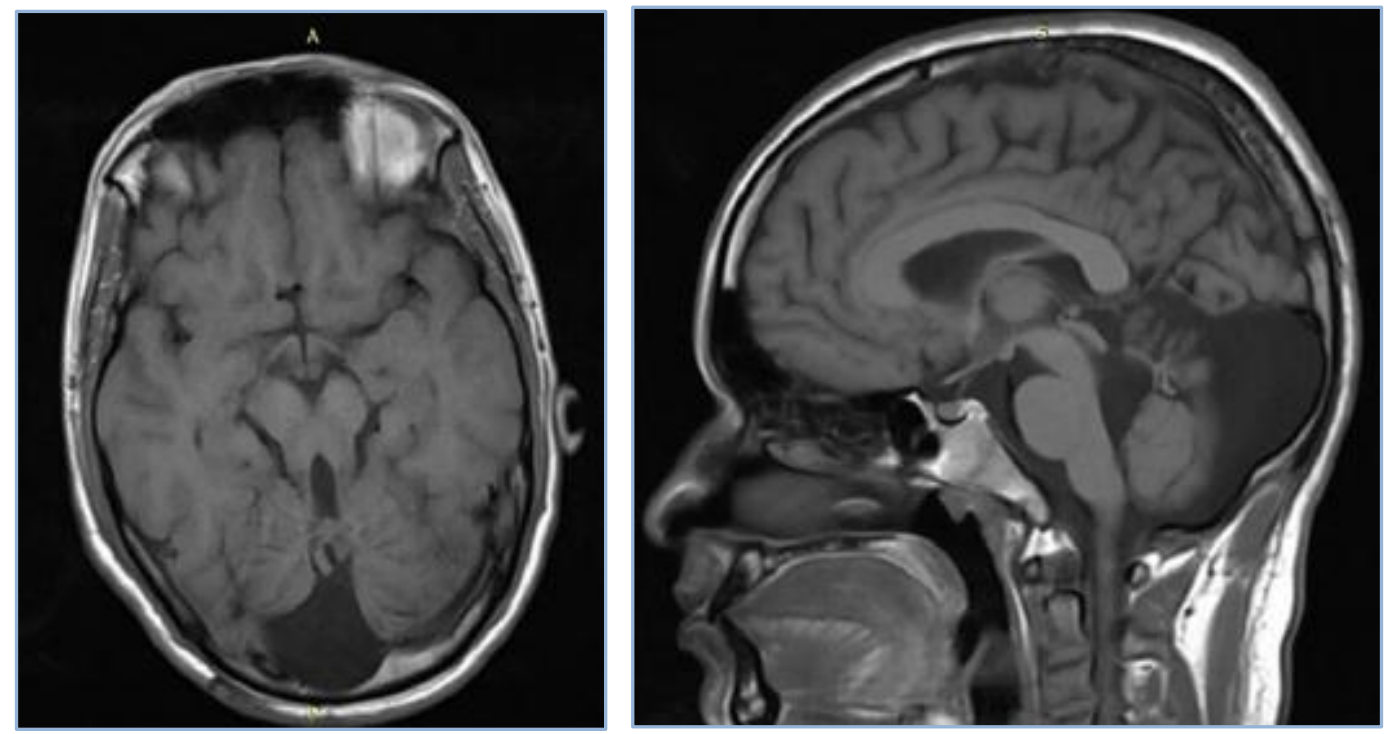

Case 3: He is a 32 years old male, brother of the aforementioned cases, with developmental delay. He could hold his head steady while sitting at age of one year and could sit independently at age of two years; he has walked without help at age of 3 year. Tooth eruption occurred at age of one year. He suffers from bilateral poor vision. His limb forces and deep tendon reflexes were normal, but he had wide gait and ataxia.

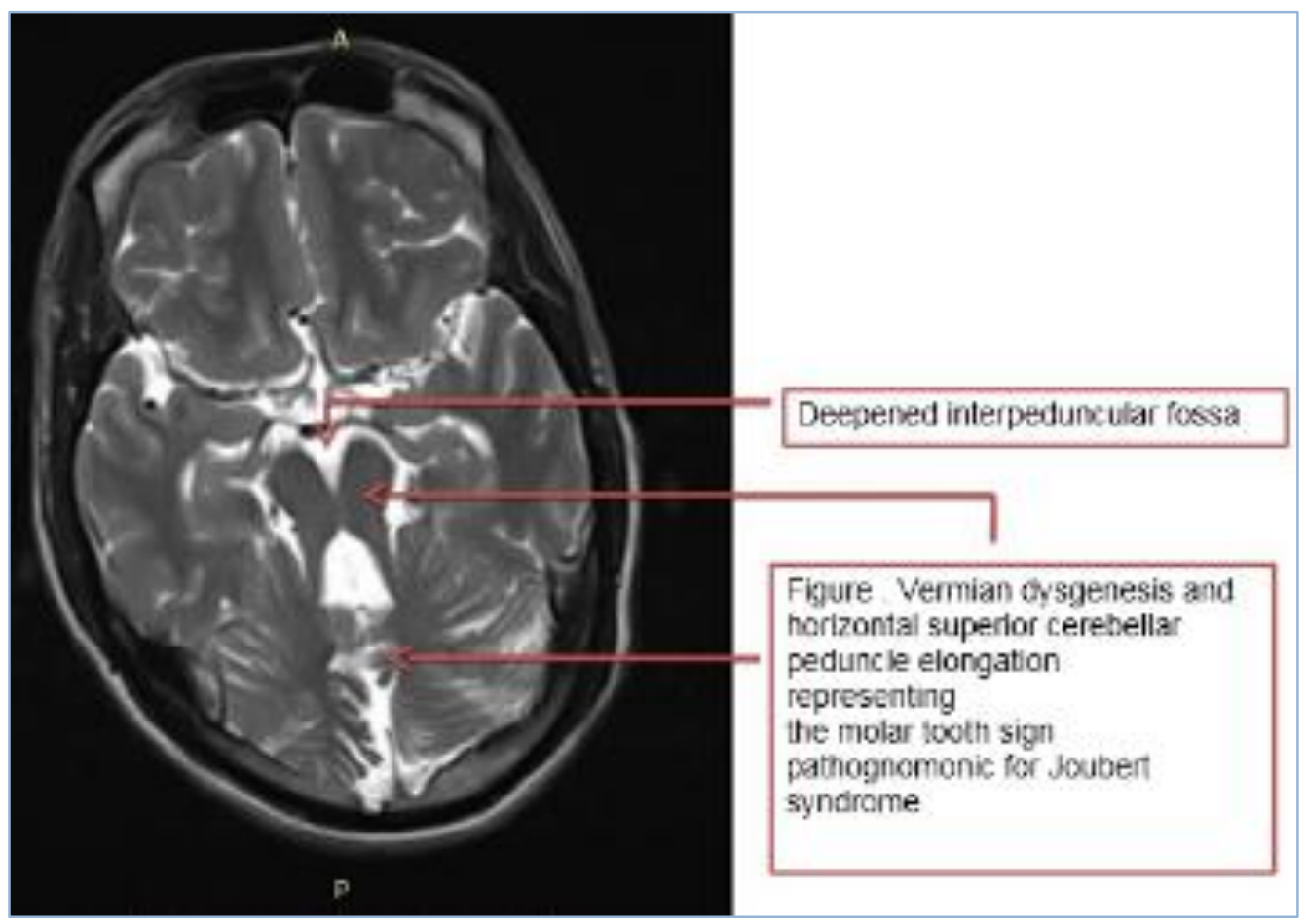




\section{CASE REPORT}
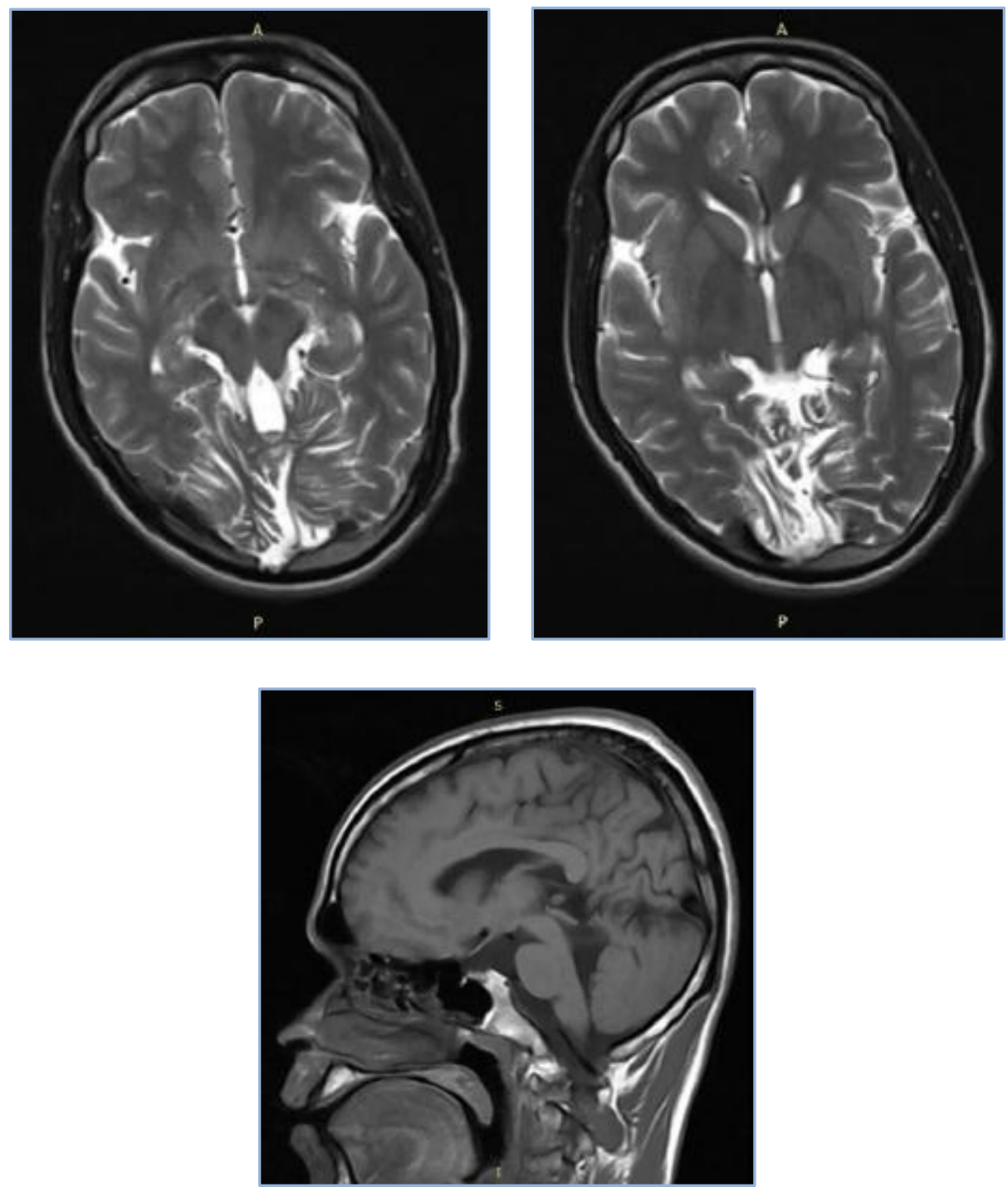

DISCUSSION: Joubert syndrome is a rare (an incidence of 1/100000) disorder of central nervous system characterized by brainstem and cerebellar malformations, hypotonia, episodic hyperapnea and apnea, neuro- ophthalmologic abnormalities, and mental retardation.(7) Dr. Marie Joubert and coworkers (1969), for the first time described described four siblings with ataxia, cognitive impairment, eye movement abnormalities, cerebellar vermis agenesis, and episodic tachypnea in a French-Canadian family. ${ }^{(8)}$

According to this initial report and other following reports, autosomal recessive inheritance has been deduced for JS and mutations in the eight ciliary/basal body genes, including INPP5E, AHI1, NPHP1, CEP290, TMEM67/MKS3, RPGRIP1L, ARL13B, and CC2D2A have been recognized in patients with JS. An additional locus, JBTS2 (or CORS2), was mapped via linkage analysis to chromosome 11.(9) Our cases confirm this inheritance pattern, because the parents and one brother were completely healthy. Maria et al. (1997) described the midbrain-hindbrain malformation observed on MRI, as a result of hypoplasia of the midline cerebellar vermis resembling the cross section of a molar tooth (Molar tooth sign' or MTS) that is considered pathognomonic for JS.(10) 
The prominent problems of our cases were ataxia, developmental delay, mental retardation and ocular disorders. All three cases had also molar tooth sign in his brain MRI. A diagnostic protocol to evaluate multiorgan involvement should be performed subsequent to detection of the molar tooth sign. Optimal management needs a multidisciplinary approach, with special consideration to respiratory and feeding disorders in newborns and infants. Cognitive and behavioral evaluations are recommended to provide neuropsychological support and rehabilitation services for young patients. ${ }^{(3)}$

In 1997, it was reported that there is an association between JS and renal cystic disease and liver fibrosis.(6) but our cases did not have any organ disorders and their ultrasonography and laboratory values were normal. We presented three siblings with similar clinical features, including ataxia, mental retardation, FTT, and strabismus. Their ataxia improved with age.

According to their poor economic state, gene analysis couldn't be performed. We could do MRI, molar tooth sign was seen that helped us to diagnose the syndrome. After one-year follow-up and rehabilitation, their abilities are much improved. We recommend that rehabilitation therapy can improve disabilities of patients with JS.

ACKNOWLEDGMENT: We would like to thank the adult males and their parents for their good cooperation. We also thank the department of radiology of guwahati medical college and hospital.

\section{REFERENCES:}

1. Ahmed J, Ali US. Joubert syndrome with nephronophthisis in neurofibromatosis type 1. Saudi J Kidney Dis Transpl 2011; 22(4):788-91.

2. Singh P, Goraya JS, Saggar K, Ahluwalia A. A report of Joubert syndrome in an infant, with literature review. J Pediatr Neurosci 2011; 6(1):44-7.

3. Brancati F, Dallapiccola B, Valente EM. Joubert Syndrome and related disorders. Orphanet J Rare Dis 2010; 5:20.

4. Malaki M, Nemati M, Shoaran M. Joubert syndrome presenting as unilateral dysplastic kidney, hypotonia, and respiratory problem. Saudi J Kidney Dis Transpl 201; 23(2):325-9.

5. Louie CM, Gleeson JG. Genetic basis of Joubert syndrome and related disorders of cerebellar development. Hum Mol Genet 2005; 15; 14 Spec No. 2:R235-42.

6. Gill H, Muthusamy B, Atan D, Williams C, Ellis M. Joubert syndrome presenting with motor delay and oculomotor apraxia. Case Rep Pediatr 2011; 2011:262641.

7. Duldulao NA, Lee S, Sun Z. Cilia localization is essential for in vivo functions of the Joubert syndrome protein Arl13b/Scorpion. Development2009; 136(23):4033-42.

8. Parisi MA. Clinical and molecular features of Joubert syndrome and related disorders. Am J Med Genet C Semin Med Genet. 2009; 15; 151C (4):326-40.

9. Castori M, Valente EM, Donati MA, Salvi S, Fazzi E, Procopio E, et al. NPHP1 gene deletion is a rare cause of Joubert syndrome related disorders. J Med Genet 2005; 42(2):e9.

10. Maria BL, Hoang KB, Tusa RJ, Mancuso AA, Hamed LM, Quisling RG, et al. "Joubert syndrome" revisited: key ocular motor signs with magnetic resonance imaging. 


\section{CASE REPORT}

\section{AUTHORS:}

1. Dipu Bhuyan

2. Pankaj Kr. Patel

3. Rohit Kr. Chandak

4. Sushant Agarwal

5. Sudip Paul

\section{PARTICULARS OF CONTRIBUTORS:}

1. Associate Professor, Department of Radiology, Gauhati Medical College.

2. Junior Resident, Department of Radiology, Gauhati Medical College.

3. Junior Resident, Department of Radiology, Gauhati Medical College.

FINANCIAL OR OTHER COMPETING INTERESTS: None
4. Senior Resident, Department of Radiology, Gauhati Medical College.

5. Junior Resident, Department of Radiology, Gauhati Medical College.

\section{NAME ADDRESS EMAIL ID OF THE} CORRESPONDING AUTHOR:

Dr. Dipu Bhuyan, Associate Professor, Department of Radiology, Gauhati Medical College and Hospital, Guwahati-781022, Assam.

E-mail: dipubhuyan@gmail.com

Date of Submission: 17/08/2015.

Date of Peer Review: 18/08/2015.

Date of Acceptance: 18/09/2015.

Date of Publishing: 21/09/2015. 